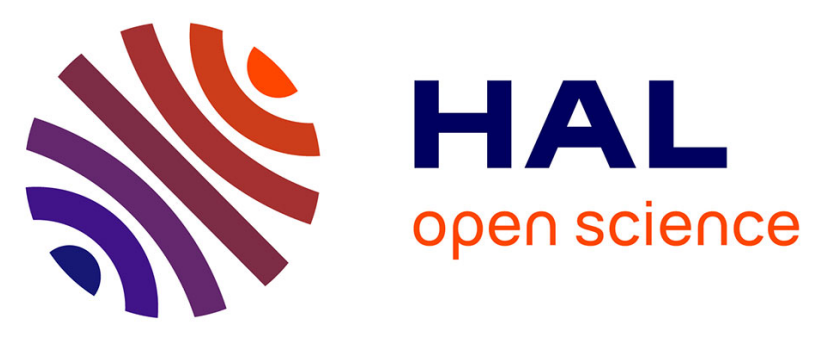

\title{
Comparison of adjustable continence therapy periurethral balloons and artificial urinary sphincter in female patients with stress urinary incontinence due to intrinsic sphincter deficiency
}

Lucas Freton, Lauranne Tondut, Isabelle Enderle, Juliette Hascoet, Andrea Manunta, Benoit Peyronnet

\section{To cite this version:}

Lucas Freton, Lauranne Tondut, Isabelle Enderle, Juliette Hascoet, Andrea Manunta, et al.. Comparison of adjustable continence therapy periurethral balloons and artificial urinary sphincter in female patients with stress urinary incontinence due to intrinsic sphincter deficiency. International Urogynecology Journal, 2018, 29 (7), pp.949-957. 10.1007/s00192-017-3544-8 . hal-01811040

HAL Id: hal-01811040

https://hal-univ-rennes1.archives-ouvertes.fr/hal-01811040

Submitted on 3 Sep 2018

HAL is a multi-disciplinary open access archive for the deposit and dissemination of scientific research documents, whether they are published or not. The documents may come from teaching and research institutions in France or abroad, or from public or private research centers.
L'archive ouverte pluridisciplinaire HAL, est destinée au dépôt et à la diffusion de documents scientifiques de niveau recherche, publiés ou non, émanant des établissements d'enseignement et de recherche français ou étrangers, des laboratoires publics ou privés. 
Comparison of Adjustable Continence Therapy periurethral balloons and artificial urinary sphincter in female patients with stress urinary incontinence due to intrinsic sphincter deficiency

Lucas FRETON ${ }^{1}$; Lauranne TONDUT ${ }^{1}$; Isabelle ENDERLE ${ }^{1}$; Juliette HASCOET ${ }^{1,2}$;

1: Service d'Urologie, CHU Rennes, 35000 Rennes, FRANCE

2: Equipe thématique INPHY CIC 1414 et INSERM UMR 991, Université Rennes 1, 35000 Rennes, France

Corresponding Author:

Lucas Freton

Service d'urologie

Hopital Pontchaillou

2 rue Henri Le Guilloux

5035000 Rennes, France

51 mail: lucas.freton@gmail.com

FINANCIAL DISCLAIMER/CONFLICT OF INTEREST: Benoit Peyronnet is 54 consultant and speaker bureau for Boston Scientific. Other authors have nothing to 55 disclose. 
57 Authors' contribution to the Manuscript :

58 L. FRETON: Data collection, Manuscript writing

59 L. TONDUT: Data collection

60 I. ENDERLE: Data collection

61 J. HASCOET: Project development

62 A. MANUNTA: Project development

63 B. PEYRONNET: Project development, Manuscript editing

64

65 Abstract word count: 250

66 Text word count: 3137

67 


\section{Abstract}

Objective: To compare the outcomes of the $A C T \circledR$ device to the ones of the artificial urinary sphincter (AUS) AMS 800 in the treatment of stress urinary incontinence due to sphincter deficiency in women

Methods: All the women who underwent a surgical treatment for stress urinary incontinence due to intrinsic sphincter deficiency from 2007 to 2017 were included in a single-center retrospective study. The primary endpoint was the functional outcome. Perioperative functional parameters were compared between the two groups.

Results:

25 patients underwent an $A C T \AA$ implantation and 36 an AUS implantation. Patients in the AUS group were younger (62.9 vs. 70.4 years; $p=0.03$ ) with less comorbidity (ASA Score=3 in $12.1 \%$ vs. $33.3 \%$; $\mathrm{p}=0.005$ ). Operative time and hospital stay were shorter in the ACT ${ }^{\circledR}$ group (respectively 45.7 vs. 206.1 min; $p<0.001 ; 1.7$ vs. 7 days; $p<0.001)$. There was a higher rate of intraoperative complications in the AUS group ( $47 \%$ vs. $8 \% ; p<0.001)$ but the rates of post-operative complications were similar between both groups. The $A C T \circledast$ was associated with an increased risk of urinary retention ( $20 \%$ vs. $2.8 \%$; $p=0.04$ ). Results were in favor of AUS for: decrease in USP stress incontinence subscore (-7.6 vs. $-3.2 ; p<0.001)$, number of pads per $24 \mathrm{~h}(-4.6$ vs. $-2.3 ; p=0.002)$, PGII scale (PGII=1: $61.1 \%$ vs. $12 \% ; p<0.001$ ) and cure rate (71.4\% vs. $21.7 \% ; p<0.001)$ 
92 Conclusion: In the present series, keeping in mind significantly different baseline 93 characteristics, AUS implantation was associated with better functional outcomes 94 than the $\mathrm{ACT}{ }^{\circledR}$ in female patients with stress urinary incontinence due to intrinsic 95 sphincter deficiency but with higher intraoperative complications rate, longer 96 operative time and length of stay.

97

98 Keywords (MeSH): artificial urinary sphincter; urinary incontinence; sphincter 99 deficiency; surgery

100

101 Brief summary: Artificial Urinary Sphincter and periurethral balloons are two options 102 for female patients with intrinsic sphincter deficiency according to their health status. 
Stress urinary incontinence due to intrinsic sphincter deficiency is usually defined as the combination of a low urethral closure pressure, loss of urethral mobility, and a

108 negative Marshall/Bonney test (urine leakage on straining or coughing not corrected

109 by urethral support) [1;2]. In daily practice, this condition is usually seen in two different populations: female patients who failed previous anti-incontinence surgical procedures (recurrent or persistent urinary incontinence after midurethral sling, Burch colposuspension,...) [3] or patients with neurogenic stress urinary incontinence

113 (usually due to spinal cord injury or spina bifida) [4]. The management of these

114 women remains highly controversial, fascial slings and bulking agents being the most 115 commonly used treatment option in North America [5], while in several European 116 countries, notably in France, external compression device, such as the Adjustable 117 Continence Therapy (ACT®, Uromedia Inc., MN, USA) or the artificial urinary 118 sphincter (AUS) AMS 800 (American Medical Systems, Minnetonka, MN, USA), are 119 usually favoured. While several series have assessed the outcomes of various 120 surgical treatment of intrinsic sphincter deficiency [1], studies comparing two 121 treatment options are lacking. The aim of this study was to compare the outcomes of 122 the $\mathrm{ACT}{ }^{\circledR}$ device to the one of the artificial urinary sphincter AMS 800 in the 123 treatment of stress urinary incontinence due to intrinsic sphincter deficiency in 124 women. 


\section{Methods}

Study design

All the 61 women who underwent a surgical treatment for stress urinary incontinence due to intrinsic sphincter deficiency from 2007 to 2017 were included in a single-

134 center retrospective study. Intrinsic sphincter deficiency was defined as the 135 combination of a low urethral closure pressure $(<40 \mathrm{~cm} \mathrm{H2O})$, loss of urethral 136 mobility, and a negative Marshall/Bonney test (urine leakage on straining or coughing 137 not corrected by urethral support). The artificial urinary sphincter AMS 800 was 138 considered as the standard treatment in these patients during the study period. The 139 ACT ${ }^{\circledR}$ periurethral balloons became available in our center in 2011 and was used 140 only in the following cases: moderate incontinence (subjectively defined as pad test < $141200 \mathrm{~g} / 24 \mathrm{~h}$ ), patients aged over 80 years and/or morbidly obese and/or lacking 142 manual dexterity limiting the abilty to operate the sphincter pump,...) and/or with 143 history of previous pelvic radiation therapy and/or patients who refused the 144 implantation of an artificial urinary sphincter. From 2007 to 2011, all patients were 145 offered AUS with no alternatives and from 2011 to 2017 patients with the 146 aforementioned comorbidites and those with moderate incontinence were offered 147 peri-urethral balloons and the other patients were offered an AUS (but some refused 148 and preferred to receive peri-urethral balloons). In accordance with national 149 guidelines [1], no other surgical treatment (e.g. fascial sling, bulking agents,...) was 150 used to treat intrinsic sphincter deficiency during the study period. Hence, the 151 inclusion criterion was: all female patients who underwent a surgical treatment for 152 stress urinary incontinence due to intrinsic sphincter deficiency from 2007 to 2017. 
153 The study was approved by the local ethics committee and was conducted following

154 the principles of the Helsinki declaration. Consent from all study participants was

155 obtained. The study was not supported by the industry. The primary endpoint was the

156 functional outcome categorized as: cured (complete continence, i.e. no pads used),

157 improved (decrease in number of pads per day or in urine leakage assessed through

158 pad test) or failure (no decrease in number of pads per day or urine leakage 159 assessed through pad test).

160

161

Adjustable Continence Therapy: device and surgical technique

163

164

All patients had a negative preoperative urine culture and received $2 \mathrm{~g}$ of

Cephalosporin group 2 at the beginning of the procedure as antibiotic prophylaxis.

Patients with a positive preoperative urine culture $\left(\geq 10^{3} \mathrm{CFU} / \mathrm{mL}\right)$ received antibiotic

treatment according to the sensitivity of the bacteria isolated from their urine culture

168 for a minimum period of two days before the implantation.

169

170 The ACT® kit contains two silicone elastomer balloons connected to a titanium port,

171 a seringe and a ponction needle used to inflate the device through the titanium port.

172 Balloons are available in 4 lengths from 6 to $9 \mathrm{~cm}$, which will be determined using the

173 trocar. This last tool is a part of dedicated tools with tipped stylet and a blunt-tipped

174 stylet,.

175

176 The surgical procedure was performed as previously described by others [1, 6-8].

177 The balloons were placed at each side of the bladder neck using the trocar, which 
178 was inserted using an incision in each labia majora, and the devices were pushed

179 laterally to urethra to their correct position on each side of the bladder neck, slightly 180 posterior (at 5 o'clock and 7 o'clock) which was controlled by fluoroscopy and flexible

181 cystoscopy. The balloons were filled with $0.6 \mathrm{ml}$ of an aqueous radiopaque solution

182 through the titanium port, which was placed subcutaneously in the labia majora. The

183 trocar was removed after inflation of the device, in order to avoid moving the device 184 during the removal.

185 A urethral catheter was introduced for up to 12 hours and removed before the patient was discharged. The procedure was performed as outpatient surgery when deemed

187 possible.

ACT implantations were performed by two surgeons with no previous experience of this surgery before the study period. Inflations of $0.6 \mathrm{ml}$ were performed once a month from 1 month post-operatively in outpatient clinics without any anesthesia by injecting into the titanium ports, until a satisfactory improvement was observed and up to a maximum of $7 \mathrm{ml}$ per balloon.

Artificial Urinary Sphincter: device and surgical technique

The antibiotic policy used was similar to the one of ACT implantations (see above). The device used was the AMS 800 in all cases. The surgical techniques used were

199 those previously described and followed the same principles regardless of the approach [9]. Briefly, the Retzius space was dissected until the bladder neck and the endopelvic fascia was opened on both sides of the urethra. The bladder neck was then dissected from the vagina below the periurethral fascia just below the level of 
203 the catheter balloon. The surgeon introduced two fingers of his left hand into the 204 vagina to help the dissection. At the end of the dissection the bladder was filled with 205 saline stained with methylene blue to verify the integrity of the bladder neck. The 206 bladder neck circumference was measured using a measuring tape. The cuff was 207 then positioned around the bladder neck. The pump was implanted in one of the labia 208 majora and the balloon in the prevesical space. An open approach was used from 2092007 to 2012 with a few laparoscopic cases over this period. From 2012 to 2017, all 210 implantations were performed through a robot-assisted approach. A single surgeon 211 (AM) highly experienced in functional urology performed all open and laparoscopic 212 cases. He was then involved as the assistant surgeon on the surgical field for the 213 robotic implantations while two consecutive surgeons were performing the dissection 214 at the console: a first surgeon highly-experienced in robotic surgery (SV; > 600 robot215 assisted radical prostatectomy at the beginning of the present study) performed the 216 first ten cases and a second surgeon, (BP, a young fellow who had performed only 21720 robotic procedures before his first robotic AUS implantation) performed the 218 subsequent cases.

219 The AUS were deactivated at the time of implantation and the urethral catheter was 220 removed 2 days after surgery, bladder ultrasound was carried out to confirm 221 adequate bladder voiding after catheter removal. Patients returned 6 weeks later for 222 activating and learning to use the sphincter. 
226 All patients underwent a complete work-up before surgery including: urodynamics, 227 urethrocystoscopy, 3 days bladder diary, and pad test. The preoperative assessment 228 also comprised a clinical interview, an urogynaecological examination and the 229 Urinary Symptoms Profile (USP) [10] and the Internation Consultation on 230 Incontinence Questionnaire Short Form (ICIQ-SF) questionnaires [11] (from 2011 to 231 2017). Neurogenic stress urinary incontinence was defined as stress urinary 232 incontinence in a patients with spinal cord injury or spina bifida.

233 Follow-up involved an outpatient visit at 3 months, 6 months and 1 year post234 operatively and then annually with a clinical examination, a 3 days bladder diary and 235 an uroflowmetry with ultrasound measurement of post-void residual urine volume. An 236 urodynamic testing was performed 3 months after AUS implantation to measure post237 operative urethral closure pressure but was not performed routinely after ACT ${ }^{\circledR}$ 238 implantation (only in case of persistent urinary incontinence after inflation of up to 5 $239 \mathrm{ml}$ per balloon).

240 Postoperative complications were graded using the Clavien-Dindo classification [12] 241 and were reported according to the EAU guidelines [13]. Failure was defined as 242 explantation of the AUS device and divided into two categories: mechanical failure 243 (perforation of any parts of the AUS or pump malfunction) and nonmechanical failure 244 (cuff erosion, infection, pain, insufficient pressure). Hence, failure and continence 245 status were analyzed separately and failure defined only the impossibility of 246 maintaining the device in situ. Acute urinary retention was defined as a post-void 247 residual volume $>150 \mathrm{ml}$ postoperatively spontaneously resolving within the first 3 248 months after surgery. Chronic urinary retention was defined as the persistence of a 249 post-void residual volume $>150 \mathrm{ml}$ greater than three months after the implantation. 
250 All urinary retentions were managed by clean-intermittent self-catheterizations (4 to 6 251 per day).

252

253 Statistical analysis

254

255 Perioperative and functional parameters were compared between the two groups. 256 Means and standard deviations were reported for continuous variables, and 257 proportions for nominal variables. Comparisons between groups were performed 258 using the $x^{2}$ test or Fisher's exact test for discrete variables, and Mann-Whitney test 259 for continuous variables. Change of continuous variables over time was assessed 260 using the McNemar test. Time to failure were estimated using the Kaplan-Meier 261 method and compared between both groups using the log-rank test. Statistical 262 analyses were performed using JMP v.12.0 software (SAS Institute Inc., Cary, NC, 263 USA). All tests were two-sided with a level of $p<0.05$ considered statistically 264 significant. 


\section{Results}

Patients' characteristics

270

271 Over the study period, 61 patients were screened and all met the inclusion criterion: 27225 underwent an $A C T \AA$ implantation and 36 an AUS implantation. The study flow273 chart is shown in figure 1. The patients' characteristics are summarized in table 1. 274 Patients in the AUS group were younger (62.9 vs. 70.4 years; $p=0.03$ ) with less 275 comorbidity (ASA Score=3 in $12.1 \%$ vs. 33.3\%; $p=0.005$ ) and none had a history of 276 previous pelvic radiation therapy conversely to those in the ACT® group (0\% vs. $27720 \% ; p=0.009)$. More patients undergoing an AUS implantation had failed previous 278 midurethral sling (66.7\% vs. $40 \%$; $p=0.04)$ but the rate of neurogenic stress urinary 279 incontinence was comparable between both groups (13.9\% vs. 4\%; $p=0.39)$ and the 280 maximum urethral closure pressure did not differ significantly between the AUS and ACT ${ }^{8}$ groups (27.3 vs. $28.8 \mathrm{cmH} 2 \mathrm{O} ; \mathrm{p}=0.61$ ). The proportion of patients who had undergone a second midurethral sling was also similar in both groups $(27.8 \%$ vs. 13.6\%; $p=0.21)$. The reasons for $A C T \AA$ implantations were as follows: moderate incontinence in five patients (20\%), comorbidites in 10 patients (40\%) and 10 patients were offered an AUS but refused and then underwent implantation of $A C T \AA(40 \%)$. Eight and five patients in the ACT and AUS group respectively had not undergone any anti-incontinence surgical procedure (32\% vs. $13.9 \%$; $=0.12)$.

Perioperative outcomes

291 Operative time was shorter in the $A C T \AA$ group (45.7 vs. $206.1 \mathrm{~min} ; \mathrm{p}<0.001$ ) and so 292 was the length of hospital stay (1.7 vs. 7 days; $p<0.001)$. There was a higher rate of 
293 intraoperative complications in the AUS group (47\% vs. 8\%; $p<0.001)$. The two 294 intraoperative complications in the $\mathrm{ACT}{ }^{\circledR}$ group were 1 bladder neck injury and 1 295 vaginal injury. The 17 intraoperative complications in the AUS group were 10 bladder 296 neck injuries and 7 vaginal injuries. The rates of post-operative complications (40\% 297 vs. 47.2\%; $p=0.57$ ) and of major post-operative complications (8\% vs. 19.4\%; $298 p=0.28)$ did not differ significantly between both groups. There were two Clavien $3 a$ 299 complications in the ACT ${ }^{\circledR}$ group which were early vaginal erosions associated with 300 a device infection which required explantation under local anesthesia in both cases. 301 In the AUS group, seven clavien 3b complications occurred; 5 device infections and 302 two large erosions which required all an explantation of the AUS under general 303 anesthesia. The last major complication in the AUS group was a device infection, 304 which occurred after a change of a first sphincter that got infected and treated 305 conservatively. It was almost always associated with a bladder neck injury during the 306 procedure. No Clavien 4 or 5 complications occurred in both groups. After a mean follow-up of 44.3 months in the AUS group (vs 22.3 months in the ACT® group; $308 p=0.02)$ the explantation rate were similar in both groups $(19.4 \%$ vs. $20 \%$; $p=0.99)$. 309 All five explantations in the $A C T \circledast$ group were due to non-mechanical failure: It was 310 due to device infection two cases, to symptoms worsening in two cases and in one 311 case, $A C T \circledast$ were explanted before implantation of an AUS. Explantations in the AUS 312 group were due to non-mechanical failure: Five were due to device infections; one to 313 large vaginal erosion and one was explanted because of a bladder neck erosion. 314 When a mechanical failure occurred, we managed the situation with a surgical 315 revision and it has always been done successfully. Time-to-failure is shown in figure 3162 (12-months cumulative failure rate: $14 \%$ in the AUS group vs $22 \%$ in the ACT® 317 group; $p=0.42$ ). 
Functional outcomes

321 The mean number of inflations in the $A C T \circledast$ group was 2.9 per balloon and the mean

322 final volume of each balloon was $3.4 \mathrm{ml}$. In the AUS group a $61-70 \mathrm{~cm} \mathrm{H} 2 \mathrm{O}$ pressure 323 balloon was used in all except one case $(71-80 \mathrm{~cm} \mathrm{H} 2 \mathrm{O})$ and the median cuff size 324 was $70 \mathrm{~mm}$. The decrease in USP stress incontinence subscore was significantly 325 greater in the AUS group (-7.6 vs. -3.2; $p<0.001$; supplementary figure 1 ) and so was 326 the decrease in mean number of pads per $24 \mathrm{~h}(-4.6$ vs. $-2.3 ; p=0.002$; see table 3$)$. 327 The Patient-Global Impression of Improvement (PGII) [14] was better in the AUS 328 group (PGII=1: $61.1 \%$ vs. $12 \% ; p<0.001)$ as was the rate of patients cured $(71.4 \%$ 329 vs. $21.7 \% ; p<0.001$ ). Five patients in the $A C T \circledast$ group required the use of clean330 intermittent self-catheterization postoperatively, at least for some time, compared to 331 only one in the AUS group ( $20 \%$ vs. $2.8 \% ; p=0.04)$. Two of the five patients who experienced urinary retention in the $A C T \circledast$ group complained from this condition so

333 their balloons were partly deflated and they recovered spontaneous voiding in both 334 case.

Subgroup of persistent/recurrent stress urinary incontinence after midurethral slings

338 In this subgroup, no patients in the ACT® group had undergone previous pelvic 339 radiation therapy. Mean age was similar in both groups (71.7 vs. $66.4 ; p=0.23$; see 340 table 4) and the maximum urethral closure pressure of patients who underwent an 341 AUS or an $\mathrm{ACT} \circledast$ implantations were comparable (24.9 vs. $26.4 \mathrm{~cm} \mathrm{H} 2 \mathrm{O} ; \mathrm{p}=0.64$ ).

342 The proportion of patients who had undergone a second midurethral sling did not 
343 differ significantly between both groups ( $37.5 \%$ vs. $10 \% ; p=0.21)$. The rate of intra344 operative complications remained higher in the AUS group ( $54.2 \%$ vs. $10 \%$; $p=0.02$ ). 345 The rate of post-operative complications tended to be higher in the AUS group 346 (54.2\% vs. $20 \% ; \mathrm{p}=0.13)$. The explantation rate did not differ significantly between 347 the two groups $(30 \%$ vs. $25 \% ; p=0.99)$. AUS outperformed $A C T \circledast$ in terms of 348 functional outcomes with a higher cure rate $(66.7 \%$ vs. $30 \% ; p=0.04)$ and a greater 349 decrease in USP stress incontinence subscore (-8 vs. $-5.3 ; p=0.003)$.

350 


\section{Discussion}

353 According to the International Consultation on Urological Diseases (ICUD), stress

354 urinary incontinence would affect from 5 to $15 \%$ and up to $30 \%$ in women over 70 year old [15].. Two decades ago, the works of Ulmsten and DeLancey has changed

356 the understanding of stress urinary incontinence by outlining the distinct role of

357 urethral support and function of urethral muscles $[16 ; 17]$. This gave birth to the concept of intrinsic sphincter deficiency meaning an impaired sphincter functioning due to loss of elasticity and coaptation [18]. While most of stress urinary incontinence in female patients is mainly due to urethral hypermobility, the exact proportion of

361 these women who suffer from some degree of intrinsic sphincter deficiency remain 362 unknown [1]. The optimal management of women with stress urinary incontinence due to intrinsic sphincter deficiency is still a matter of debate. While the American Urological Association (AUA) 2017 guidelines [19] do not mention the role of AUS or ACT ${ }^{\circledR}$ in their treatment algorithm; the European Association of Urology (EAU) 2017 guidelines consider that they might have a role but that secondary synthetic sling, colposuspension or autologous sling are first options for women with complicated 368 stress urinary incontinence [20]. The French Association of Urology (AFU) recommends AUS as the gold-standard treatment for severe SUI due to intrinsic sphincter deficiency and ACT® as a possible alternative in these patients [21]. These

371 heterogeneous recommendations may be explained by the paucity of data in the 372 literature. To date, no study has compared fascial slings to AUS or ACT®. To our 373 knowledge, the present series is one of the first to compare two different techniques 374 of intrinsic sphincter deficiency management in female patients and the first to compare these two specific devices. In the present study, AUS implantation was associated with better functional outcomes than $A C T \AA$ implantation in female 
377 patients with stress urinary incontinence due to intrinsic sphincter deficiency but with 378 higher intraoperative complications rate, longer operative time and prolonged length 379 of stay.

380 The morbidity of AUS implantation was higher than the one of $A C T \AA$, despite 381 comparable post-operative complications rate. The high morbidity of the AUS in 382 female patients has often been assumed to be the key factor that has limited its widespread [4]. This high complication rate might be due to the technically challenging dissection of the bladder neck, located deep in the pelvis with an urethral-vaginal septum often difficult to open due to the amount of previous surgical procedures. In recent years, the use of a robotic approach has been proposed to facilitate AUS implantation in women [22]. In a preliminary report, robotic AUS implantation appeared to decrease post-operative complications rate, blood loss and length of stay with a trend towards lower intraoperative complications compared to the open approach. Hence, one may assume that the difference we observed in terms of morbidity between AUS and $A C T \AA$ may be tempered with a purely robotic 392 AUS cohort (our cohort included a mix of open, laparoscopic and robotic AUS 393 implantation).

It is now widely accepted through the urogynecology community that rather than looking for an objective cure in every case, physicians should adapt their treatments to patient's expectation and profile [23]. Our results are of interest in that regard as 398 AUS, by outperforming $A C T \AA$ in terms of functional outcomes, might be an appropriate option for patients with intrinsic sphincter deficiency seeking for cure of their urinary incontinence. Conversely, with its fair safety profile despite older patients 401 with more comorbidity and previous pelvic radiation therapy (20\%), the ACT® could 
402 be a reliable option for patients looking for improvement of their urinary incontinence.

403

404 Another point of interest of this study is that the ACT® was associated with an 405 increased risk of urinary retention postoperatively. This finding emphasizes an 406 important point of strength of the AUS, as it is the only therapy of stress urinary 407 incontinence due to intrinsic sphincter deficiency increasing urethral pressure during 408 storage while maintaining a low urethral resistance during voiding by opening the 409 device cuff. Indeed, the mechanism of action of ACT® is similar to the one of other 410 treatment options such as fascial slings or bulking agents, by creating a permanent 411 (ie that cannot be relieved) external compression over the urethra to preserve 412 continence [5]. Long-term data regarding the impact of this increase bladder outlet 413 resistance on detrusor contractility are lacking [24] but by analogy to what is seen in 414 men with long-lasting benign prostate obstruction, one could assume that this external compression treatment options (i.e. $\mathrm{ACT}{ }^{\circledR}$, bulking agent or fascial sling) may lead to detrusor underactivity in the long-term. The benefits of ACT over bulking 417 agents or fascial slings in that regard is that the obstruction can be fully relieved, as 418 outlined in our series, by deflating the balloons.

420 Our study had several limitations that should be emphasized. Firstly, its retrospective 421 and nonrandomized design could have partly flawed our results, notably because of 422 an obvious selection bias with patients' characteristics differing in both groups, which 423 we aimed to balance by performing a subgroup analysis. Another limitation is the 424 relatively small sample size of our series, which may lead to a lack of statistical 425 power and which prevented to perform multivariate analyses. We reported the early 426 experience of a medium volume center for the two techniques and our findings may 
427 have differed if coming from a tertiary volume center with a larger experience in AUS 428 and $A C T \AA$ implantations. There is still no consensus regarding the definition of 429 intrinsic sphincter deficiency and the one we used in this study could therefore be a 430 matter of debate. The various approaches used in the AUS group (i.e. open, 431 laparoscopic, robot-assisted) might have been a confounder when analysing 432 perioperative outcomes. Despite these drawbacks, we believe that the comparative 433 data we provide are of value while the optimal management of SUI due to intrinsic 434 sphincter deficiency remains to be determined.

\section{Conclusion}

437 In the present series, the patients in the two groups differed significantly in age, ASA 438 score, history of pelvic radiation therapy and history of previous midurethral sling, 439 which might have biased our findings. AUS implantation was associated with better 440 functional outcomes than the $\mathrm{ACT} \circledast$ in female patients with stress urinary 441 incontinence due to intrinsic sphincter deficiency but with higher intraoperative 442 complications rate, longer operative time and length of stay. Post-operative 443 complications and explantation rates were similar between both groups. Future 444 prospective randomized trials are needed to better define treatment algorithms of 445 female patients with stress urinary incontinence due to intrinsic sphincter deficiency. 


\section{Abbreviations}

449 ACT : Adjustable Continence Therapy

450 AMS: American Medical System

451 ASA : American Society of Anesthesiologists

452 AUA : American Urological Association

453 AUS : Artificial Urinary Sphincter

454 EAU : European Association of Urology

455 ICIQ-SF: Internation Consultation on Incontinence Questionnaire Short Form

456 ICUD : International Consultation on Urological Diseases

457 PGII: Patient-Global Impression of Improvement

458 SUI : Stress Urinary Incontinence

459 USP : Urinary Symptoms Profile

460

461

\section{References}

462

463 1. Cour, F., L. Le Normand, J.-F. Lapray, J.-F. Hermieu, L. Peyrat, R. Yiou, L. Donon, 464 L. Wagner, A. Vidart, and the French committee of female urology. "[Intrinsic 465 sphincter deficiency and female urinary incontinence)." Prog Urol 25, no. 8 (June 466 2015): 437-54. doi:10.1016/j.purol.2015.03.006.

467

468 2. Costa, Pierre, Gregoire Poinas, Kamel Ben Naoum, Khalid Bouzoubaa, Laurent 469 Wagner, Laurent Soustelle, Michel Boukaram, and Stéphane Droupy. "Long-Term 470 Results of Artificial Urinary Sphincter for Women with Type III Stress Urinary 471 Incontinence." European Urology 63, no. 4 (April 2013): 753-58. 472 doi:10.1016/j.eururo.2012.03.008.

473

474 3. Lo, Tsia-Shu, Leng Boi Pue, Yiap Loong Tan, and Pei-Ying Wu. "Risk Factors for 475 Failure of Repeat Midurethral Sling Surgery for Recurrent or Persistent Stress 
476 Urinary Incontinence." International Urogynecology Journal 27, no. 6 (June 2016):

477 923-31. doi:10.1007/s00192-015-2912-5.

478

479

4. Chartier-Kastler, Emmanuel, Philip Van Kerrebroeck, Roberto Olianas, Michel Cosson, Eric Mandron, Emmanuel Delorme, and François Richard. "Artificial Urinary Sphincter (AMS 800) Implantation for Women with Intrinsic Sphincter Deficiency: A Technique for Insiders?" BJU International 107, no. 10 (May 2011): 1618-26. doi:10.1111/j.1464-410X.2010.09610.x.

5. Nadeau, Geneviève, and Sender Herschorn. "Management of Recurrent Stress Incontinence Following a Sling." Current Urology Reports 15, no. 8 (August 2014): 427. doi:10.1007/s11934-014-0427-0.

6. Vayleux, B., F. Luyckx, S. Thélu, J. Rigaud, O. Bouchot, G. Karam, and L. Le Normand. "[Adjustable Continence Therapy in women, middle term follow-up and a new technique for balloon positioning]." Progres En Urologie: Journal De l'Association Francaise D'urologie Et De La Societe Francaise D'urologie 20, no. 7 (July 2010): 520-26. doi:10.1016/j.purol.2010.01.010.

7. Phé, Véronique, Kien Nguyen, Morgan Rouprêt, Vincent Cardot, Jérôme Parra, and Emmanuel Chartier-Kastler. "A Systematic Review of the Treatment for Female Stress Urinary Incontinence by $\mathrm{ACT} \circledast$ Balloon Placement (Uromedica, Irvine, CA, USA)." World Journal of Urology 32, no. 2 (April 2014): 495-505. doi:10.1007/s00345-013-1117-0.

8. Kocjancic, Ervin, Simone Crivellaro, Stefania Ranzoni, Daniele Bonvini, Barbara Grosseti, and Bruno Frea. "Adjustable Continence Therapy for Severe Intrinsic Sphincter Deficiency and Recurrent Female Stress Urinary Incontinence: Long-Term Experience." The Journal of Urology 184, no. 3 (September 2010): 1017-21. doi:10.1016/j.juro.2010.05.024.

9. Peyronnet, Benoit, Sébastien Vincendeau, Lauranne Tondut, Karim Bensalah, Mireille Damphousse, and Andréa Manunta. "Artificial Urinary Sphincter Implantation in Women with Stress Urinary Incontinence: Preliminary Comparison of Robot- 
510

511

512

513

514

515

516

517

518

519

520

521

522

523

524

525

526

527

528

529

530

531

532

533

534

535

536

537

538

539

540

541

Assisted and Open Approaches." International Urogynecology Journal 27, no. 3 (March 1, 2016): 475-81. doi:10.1007/s00192-015-2858-7.

10. Haab, François, François Richard, Gérard Amarenco, Patrick Coloby, Benoit Arnould, Khadra Benmedjahed, Isabelle Guillemin, and Philippe Grise. "Comprehensive Evaluation of Bladder and Urethral Dysfunction Symptoms: Development and Psychometric Validation of the Urinary Symptom Profile (USP) Questionnaire." Urology 71, no. 4 (April 2008): 646-56. doi:10.1016/j.urology.2007.11.100.

11. Avery, Kerry, Jenny Donovan, Tim J. Peters, Christine Shaw, Momokazu Gotoh, and Paul Abrams. "ICIQ: A Brief and Robust Measure for Evaluating the Symptoms and Impact of Urinary Incontinence." Neurourology and Urodynamics 23, no. 4 (2004): 322-30. doi:10.1002/nau.20041.

12. Dindo, Daniel, Nicolas Demartines, and Pierre-Alain Clavien. "Classification of Surgical Complications." Annals of Surgery 240, no. 2 (August 2004): 205-13. doi:10.1097/01.sla.0000133083.54934.ae.

13. Mitropoulos, Dionysios, Walter Artibani, Markus Graefen, Mesut Remzi, Morgan Rouprêt, Michael Truss, and European Association of Urology Guidelines Panel. "Reporting and Grading of Complications after Urologic Surgical Procedures: An Ad Hoc EAU Guidelines Panel Assessment and Recommendations." European Urology 61, no. 2 (February 2012): 341-49. doi:10.1016/j.eururo.2011.10.033.

14. Yalcin, Ilker, and Richard C. Bump. "Validation of Two Global Impression Questionnaires for Incontinence." American Journal of Obstetrics and Gynecology 189, no. 1 (July 2003): 98-101. 15. Incontinence. Paul Abrams, Linda Cardozo, Saad Khoury, Alan Wein. 5th Edition 2013. ISBN : 978-9953-493-21-3 
16. DeLancey, John O. L. "The Pathophysiology of Stress Urinary Incontinence in

543 Women and Its Implications for Surgical Treatment." World Journal of Urology 15, no.

544 (October 1, 1997): 268-74. doi:10.1007/BF02202011.

546 17. Petros, Peter E. Papa, Ulf I. Ulmsten, and John Papadimitriou. "The Autogenic 547 Ligament Procedure: A Technique for Planned Formation of an Artificial Neo548 Ligament." Acta Obstetricia et Gynecologica Scandinavica 69, no. S153 (January 1, 549 1990): 43-51. doi:10.1111/j.1600-0412.1990.tb08031.x.

18. McGuire, E. J. "Diagnosis and Treatment of Intrinsic Sphincter Deficiency." International Journal of Urology: Official Journal of the Japanese Urological Association 2 Suppl 1 (April 1995): 7-10; discussion 16-18.

19. AUA Guidelines. Kathleen C. Kobashi, MD, FACS, FPMRS; Michael E. Albo, MD; Roger R. Dmochowski, MD; David A. Ginsberg, MD; Howard B. Goldman, MD; Alexander Gomelsky, MD; Stephen R. Kraus, MD, FACS; Jaspreet S. Sandhu, MD; Tracy Shepler; Jonathan R. Treadwell, PhD; Sandip Vasavada, MD; Gary E. Lemack, MD. http://www.auanet.org/guidelines/stress-urinary-incontinence-(sui)-new560 (aua/sufu-guideline-2017)

20. EAU guidelines. F.C. Burkhard (Chair), J.L.H.R. Bosch, F. Cruz, G.E. Lemack, A.K. Nambiar, N. Thiruchelvam, A. Tubaro Guidelines Associates: D. Ambühl, D. Bedretdinova, F. Farag, B.B. Rozenberg https://uroweb.org/guideline/urinaryincontinence/

21. Recommandations AFU - Prog Urol, 2010, 20, suppl. 2 569 http://www.urofrance.org/base-bibliographique/traitement-de-lincontinence-urinaire-

570 feminine-non-neurologique

22. Fournier, Georges, Pierre Callerot, Maxime Thoulouzan, Antoine Valeri, and 573 Marie-Aimee Perrouin-Verbe. "Robotic-Assisted Laparoscopic Implantation of 574 Artificial Urinary Sphincter in Women with Intrinsic Sphincter Deficiency Incontinence: 
575 Initial Results." Urology 84, no. 5 (November 2014): 1094-98. 576 doi:10.1016/j.urology.2014.07.013.

577

578 23. Riss, Paul, and Julia Kargl. "Quality of Life and Urinary Incontinence in Women." 579 Maturitas 68, no. 2 (February 2011): 137-42. doi:10.1016/j.maturitas.2010.11.006. 580

581 24. Siddiqui, Zain A., Hamid Abboudi, Ruairidh Crawford, and Shahzad Shah. 582 "Intraurethral Bulking Agents for the Management of Female Stress Urinary 583 Incontinence: A Systematic Review." International Urogynecology Journal, February 584 21, 2017, 1-10. doi:10.1007/s00192-017-3278-7.

585

586

587 
Fig. 1 Study flow-chart

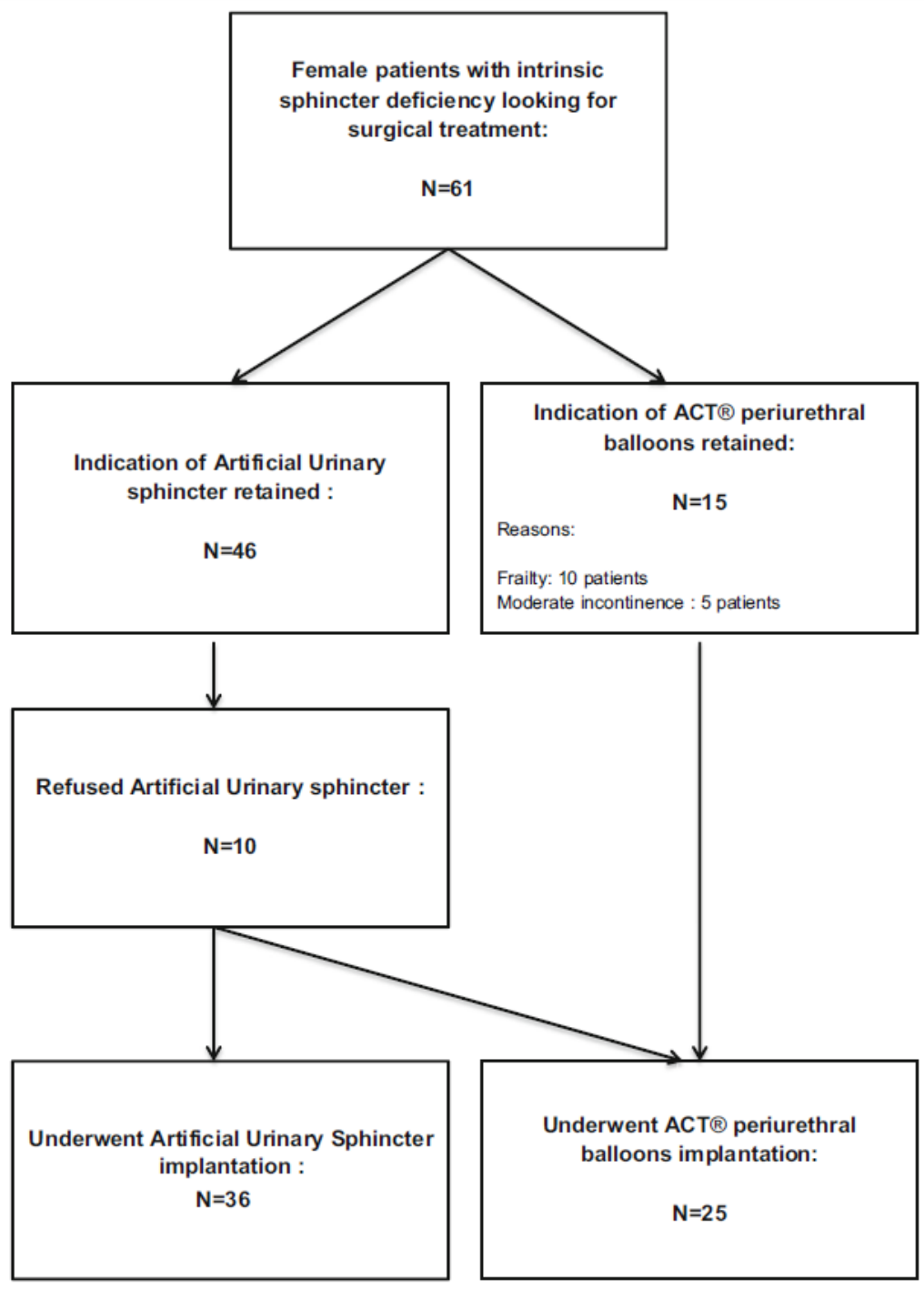


Fig. 2 Time to failure comparison

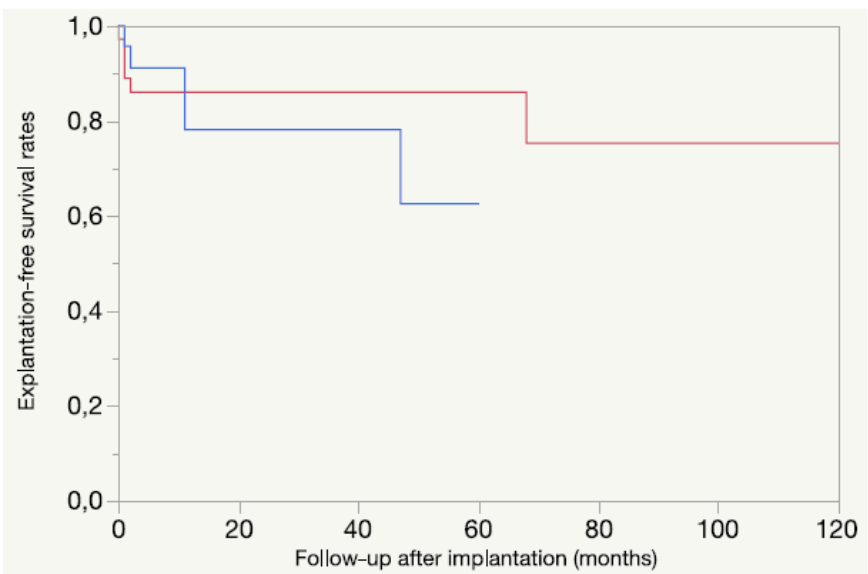

\begin{tabular}{|c|c|c|c|c|c|c|c|}
\hline \multicolumn{2}{|c|}{} & 20 months & 40 months & 60 months & 80 months & 100 months & 120 months \\
\hline \multirow{2}{*}{$\begin{array}{c}\text { ACT } \\
\mathrm{N}=25\end{array}$} & $\begin{array}{c}\text { Number at } \\
\text { risk }\end{array}$ & 11 & 6 & 3 & 0 & 0 & 0 \\
\cline { 2 - 8 } & $\begin{array}{c}\text { Number of } \\
\text { failure }\end{array}$ & 4 & 0 & 1 & 0 & 0 & 0 \\
\hline \multirow{2}{*}{$\begin{array}{c}\text { AUS } \\
\mathrm{N}=36\end{array}$} & $\begin{array}{c}\text { Number at } \\
\text { risk }\end{array}$ & 24 & 17 & 11 & 6 & 3 & 3 \\
\cline { 2 - 9 } & $\begin{array}{c}\text { Number of } \\
\text { failure }\end{array}$ & 5 & 0 & 0 & 1 & 0 & 0 \\
\hline
\end{tabular}

ACT ${ }^{\circ}$

Artificial urinary sphincter

Log-rank test : $p=0.42$

* 1 failure occured at 126 months 
Table 1 : Patients' characteristics

\begin{tabular}{|c|c|c|c|}
\hline & $\begin{array}{l}\text { ACT® } \\
N=25\end{array}$ & $\begin{array}{c}\text { Artificial urinary } \\
\text { sphincter } \\
N=36\end{array}$ & p-value \\
\hline Mean age (years) & $70.4( \pm 3.1)$ & $62.9( \pm 2.5)$ & $0.03^{*}$ \\
\hline $\begin{array}{c}\text { Body Mass Index } \\
\left(\mathrm{kg} / \mathrm{m}^{2}\right)\end{array}$ & $26.1( \pm 1.4)$ & $28.6( \pm 3.1)$ & 0.10 \\
\hline $\begin{array}{c}\text { ASA score } \\
1 \\
2 \\
3\end{array}$ & $\begin{array}{c}0(0 \%) \\
16(66.7 \%) \\
8(33.3 \%)\end{array}$ & $\begin{array}{l}10(30.3 \%) \\
19(57.6 \%) \\
4(12.1 \%)\end{array}$ & $0.005^{\star}$ \\
\hline $\begin{array}{l}\text { History of pelvic } \\
\text { radiation therapy }\end{array}$ & $5(20 \%)$ & $0(0 \%)$ & $0.009 *$ \\
\hline $\begin{array}{c}\text { History of any } \\
\text { previous pelvic } \\
\text { surgery }\end{array}$ & $19(76 \%)$ & $28(77.8 \%)$ & 0.87 \\
\hline $\begin{array}{c}\text { History of } \\
\text { previous } \\
\text { midurethral sling }\end{array}$ & $10(40 \%)$ & $24(66.7 \%)$ & $0.04^{*}$ \\
\hline $\begin{array}{c}\text { Neurogenic stress } \\
\text { urinary } \\
\text { incontinence }\end{array}$ & $1(4 \%)$ & $5(13.9 \%)$ & 0.39 \\
\hline $\begin{array}{l}\text { Maximum urethral } \\
\text { closure pressure } \\
\text { (cmH2O) }\end{array}$ & $28.8( \pm 2.7)$ & $27.3( \pm 2.3)$ & 0.61 \\
\hline
\end{tabular}

* :statistically significant 
Table 2 : Perioperative outcomes

\begin{tabular}{|c|c|c|c|}
\hline & $\begin{array}{c}\text { ACT® } \\
\mathbf{N}=\mathbf{2 5}\end{array}$ & $\begin{array}{c}\text { Artificial urinary } \\
\text { sphincter } \\
\mathbf{N}=36\end{array}$ & p-value \\
\hline $\begin{array}{c}\text { Operative time } \\
\text { (min) }\end{array}$ & $45.7( \pm 7.7)$ & $206.1( \pm 7.7)$ & $<0.001^{*}$ \\
\hline $\begin{array}{c}\text { Length of hospital } \\
\text { stay (days) }\end{array}$ & $1.7( \pm 1)$ & $7( \pm 0.9)$ & $<0.001^{*}$ \\
\hline $\begin{array}{c}\text { Intra-operative } \\
\text { complications }\end{array}$ & $2(8 \%)$ & $17(47 \%)$ & $<0.001^{*}$ \\
\hline $\begin{array}{c}\text { Post-operative } \\
\text { complications }\end{array}$ & $10(40 \%)$ & $17(47.2 \%)$ & 0.57 \\
\hline $\begin{array}{c}\text { Major post- } \\
\text { operative } \\
\text { complications } \\
\text { (Clavien } \geq 3)\end{array}$ & $2(8 \%)$ & $7(19.4 \%)$ & 0.28 \\
\hline $\begin{array}{c}\text { Explantation } \\
\text { Exp }\end{array}$ & $5(20 \%)$ & $7(19.4 \%)$ & \\
\hline
\end{tabular}

${ }^{*}$ : statistically significant 
Table 3: Functional outcomes

\begin{tabular}{|c|c|c|c|}
\hline & $\begin{array}{l}\text { ACT } ® \\
\mathrm{~N}=25\end{array}$ & $\begin{array}{c}\text { Artificial urinary } \\
\text { sphincter } \\
\mathrm{N}=36\end{array}$ & $p$-value \\
\hline $\begin{array}{c}\text { Mean number of pads } / \mathbf{2 4 h} \\
\text { Preoperatively } \\
\text { At } 6 \text { months }\end{array}$ & $\begin{array}{c}4.5( \pm 0.3) \\
2.2( \pm 0.3)^{1}\end{array}$ & $\begin{array}{l}5.2( \pm 0.3) \\
0.6( \pm 0.2)^{1}\end{array}$ & $\begin{array}{c}0.14 \\
0.002\end{array}$ \\
\hline $\begin{array}{c}\text { PGII (6 months) } \\
1: \text { Very improved } \\
2: \text { Improved } \\
3: \text { Slightly improved } \\
4: \text { Unchanged } \\
5-7: \text { Woresened }\end{array}$ & $\begin{array}{l}3(12 \%) \\
6(24 \%) \\
8(32 \%) \\
6(24 \%) \\
2(8 \%)\end{array}$ & $\begin{array}{l}22(61.1 \%) \\
5(13.9 \%) \\
2(5.6 \%) \\
6(16.7 \%) \\
1(2.8 \%)\end{array}$ & $<0.001^{*}$ \\
\hline $\begin{array}{c}\text { Complete continence at } 6 \\
\text { months }\end{array}$ & $5(21.7 \%)$ & $25(71.4 \%)$ & $<0.001^{*}$ \\
\hline $\begin{array}{l}\text { USP stress incontinence } \\
\text { sub-score (/9) } \\
\text { Preoperatively } \\
\text { At } 6 \text { months }\end{array}$ & $\begin{array}{l}7.8( \pm 0.5) \\
4.8( \pm 0.7)^{1}\end{array}$ & $\begin{array}{l}8.4( \pm 0.5) \\
0.3( \pm 0.5)^{1}\end{array}$ & $\begin{array}{c}0.22 \\
<0.001^{*}\end{array}$ \\
\hline Median follow-up (months) & $\begin{array}{c}11 \\
{[4-42.5]}\end{array}$ & $\begin{array}{c}37.5 \\
{[12.8-65.8]}\end{array}$ & 0.02 * \\
\hline
\end{tabular}

* :statistically significant

${ }^{1}$ : statistically significant change from baseline $(p<0.05)$ 
Table 4: Subgroup of recurrent/persistent incontinence after midurethral slings

\begin{tabular}{|c|c|c|c|}
\hline & $\begin{array}{l}\text { ACT } 尺 \\
N=10\end{array}$ & $\begin{array}{l}\text { Artificial urinary } \\
\text { sphincter } \\
\mathrm{N}=24\end{array}$ & $p$-value \\
\hline Mean age (years) & $71.7( \pm 3.3)$ & $66.4( \pm 2.1)$ & 0.23 \\
\hline $\begin{array}{l}\text { Maximum urethral closure } \\
\text { pressure }(\mathrm{cmH} 2 \mathrm{O})\end{array}$ & $24.9( \pm 3.5)$ & $26.4( \pm 2.5)$ & 0.64 \\
\hline $\begin{array}{l}\text { Intra-operative } \\
\text { complications }\end{array}$ & $1(10 \%)$ & $13(54.2 \%)$ & $0.02^{*}$ \\
\hline $\begin{array}{c}\text { PGII (6 months) } \\
1: \text { Very improved } \\
2: \text { Improved } \\
3: \text { Slightly improved } \\
4: \text { Unchanged } \\
5-7: \text { Woresened }\end{array}$ & $\begin{array}{l}1(10 \%) \\
3(30 \%) \\
4(40 \%) \\
1(10 \%) \\
1(10 \%)\end{array}$ & $\begin{array}{c}15(62.5 \%) \\
5(20.8 \%) \\
2(8.3 \%) \\
4(16.7 \%) \\
1(4.2 \%)\end{array}$ & $0.02^{*}$ \\
\hline $\begin{array}{l}\text { Complete continence at } 6 \\
\text { months }\end{array}$ & $3(33.3 \%)$ & 16 (66.7\%) & $0.04^{*}$ \\
\hline $\begin{array}{l}\text { USP stress incontinence } \\
\text { sub-score (/9) } \\
\text { Preoperatively } \\
\text { At } 6 \text { months }\end{array}$ & $\begin{array}{l}7.8( \pm 0.5) \\
3.5( \pm 0.6)^{1}\end{array}$ & $\begin{array}{l}8.4( \pm 0.5) \\
0.4( \pm 0.5)^{1}\end{array}$ & $\begin{array}{l}0.22 \\
0.003^{*}\end{array}$ \\
\hline Explantation & $3(30 \%)$ & $6(25 \%)$ & 0.99 \\
\hline
\end{tabular}

* :statistically significant

1 : statistically significant change from baseline $(p<0.05)$ 